\title{
Regional Ideas in International Education Organizations: The Case of SEAMEO
}

\author{
David Krogmann
}

\section{Introduction ${ }^{1}$}

Over the last decades, various regional International Organizations (IOs) have emerged as relevant yet largely uncharted actors in international education policy. One of them is the Southeast Asian Ministers of Education Organization (SEAMEO). The underrepresentation of regional organizations in contemporary research on international education policy is striking, especially when considering that SEAMEO has been a major player in education policy in Southeast Asia for decades.

\footnotetext{
${ }^{1}$ This chapter is a product of the research conducted in the Collaborative Research Center "Global Dynamics of Social Policy" at the University of Bremen. The center is funded by the Deutsche Forschungsgemeinschaft (DFG, German Research Foundation)_-project number 374666841SFB 1342.

D. Krogmann $(\bowtie)$

Institute for Intercultural and International Studies (InIIS) and Collaborative Research Centre 1342 "Global Dynamics of Social Policy”, University of Bremen, Bremen, Germany e-mail: krogmann@uni-bremen.de
} 
Despite being founded in 1965 (SEAMEO 1965), it has consistently failed to garner any attention from scholars of international education or international relations. By exploring the underlying leitmotifs and ideas that inform the discourse produced and reproduced by SEAMEO, the following chapter represents a first step toward filling this gap. How does SEAMEO conceive of education? I argue that SEAMEO follows a distinctly holistic ideal of education policy, stressing both the social as well as the economic purposes of education. While some of its inspiration may stem from the United Nations' (UN) post-2015 global sustainable development agenda in education policy, SEAMEO has championed a balanced approach toward education from its very inception. However, it has done and continues to do so with a distinct emphasis on the educational purpose of reinforcing the collectively shared cultural values and traditions of its member states, which it deems unique to Southeast Asia. The influence of regional organizations on education policy in their respective regions should not be underestimated. Indeed, the majority of international organizations active in education policy are regional organizations (Martens and Niemann 2021). Acting at the intersection of the global and the local, SEAMEO is uniquely connected with both globally oriented partner organizations, such as the United Nations Educational, Scientific, and Cultural Organization (UNESCO), and the national governments of its member states. Therefore, studying the organization's perception of education and its ideas on education policy provides valuable insights into conceptions of education in the region.

The case study presented here relies on qualitative content analysis to infer SEAMEO's ideas and leitmotifs in education policy from the organization's policy publications as well as from personal statements made by SEAMEO officials. Qualitative content analysis is a method for systematically analyzing qualitative data and deducing meaning from documents (Krippendorff 2004; Schreier 2014). Valuable objects for analysis can, in principle, include recorded communication of any form. Two main sources were used for the purpose of this chapter. First, 15 strategic education policy documents published by SEAMEO between 1970 and 2019 were deductively analyzed using a coding scheme based on the different leitmotifs in education policy presented in the introduction to this volume. Eligible documents for analysis were limited to publications 
available in English to circumvent the considerable language barriers resulting from SEAMEO using multiple official languages. To organize the data, the software MAXQDA was employed. The 185 data points acquired through this process form the basis of the analysis. Complementing this first step, a semi-structured interview with a highranking SEAMEO official was conducted in February 2020. Before engaging with the data, however, the chapter provides a brief introduction to SEAMEO, covering its organizational setup, its member states, and its cooperation with other organizations. Based on four leitmotifs in education policy, I then explore the qualitative data drawn from the documents before discussing the results. The chapter closes with a short outlook on possible implications of the evidence from this analysis.

\section{International Organizations in Education: Leitmotifs and Ideas}

This chapter rests on a few core assumptions about the role of ideas and leitmotifs in the discourses proliferated by international organizations working on education. The first is that international organizations matter. They have a distinct influence on international education policy, which manifests itself in various ways (Barnett and Finnemore 1999; Hawkins et al. 2006; Bauer 2006). One of these ways is the diffusion of norms and ideas (Barnett and Finnemore 2004); it is through this process, among others, that international organizations have become relevant actors in global education policy. Through the activities of IOs, ideas concerning what education is supposed to look like or what purpose it should serve are distributed beyond national borders. Conversely, IOs also incorporate ideas proliferated by their member states, meaning diffusion is not just a one-way road, though it is rarely possible to trace a certain idea all the way back to its very origin. Nonetheless, as ideas are such a crucial part of what makes IOs influential in global politics, research on what these ideas and leitmotifs might be is imperative.

I use the terms "leitmotif" and "idea" in the following sections. A leitmotif is a recurring theme in a given medium and, in this context, guides 
education policy. As established in the previous chapter, I follow Goldstein and Keohane's conceptualization in which an idea is a belief held by individuals (Goldstein and Keohane 1993). Leitmotifs, in turn, are comprised of sets of multiple ideas. This chapter attempts to uncover the ideas and leitmotifs proposed and reinforced by SEAMEO in its official documents. For this purpose, it relies on four basic guiding principles or leitmotifs in education (see the introduction to this volume, Chap. 1; Nagel et al. 2010).

Generally, education can be seen as a means to increase either the economic utility or the cohesiveness of a given society. These basic aims work on both the individual and the collective level. For individuals, education is supposed to enhance their skills for the labor market, thereby boosting their productivity and income. With respect to the social dimension, education is supposed to enable individuals to find self-fulfillment and develop their character to the fullest. On the collective level, education can be seen as a means to increase economic growth and provide skilled human capital. At the same time, it can also be an important tool for states and IOs to create an informed citizenry that allows its members to participate in the political process, to be aware of their rights and duties, and to achieve a cohesive, just society. These leitmotifs are of course ideal types. Also, they are not mutually exclusive, meaning that most of the time all of them will be informing the actions of a given education IO to some degree. Furthermore, the principles may be interlinked. On the individual level, skill formation and a successful career may contribute to self-fulfillment for citizens. On the collective level, a wealthy nation may have an easier time with citizen participation in the political process and in society in general given that people do not have to spend most of their time on their livelihood when there is a certain degree of wealth.

Seeing as ideas depend on the social context within which they are created and reproduced, it can be expected that region- or culture-specific ideas are at play within regional education IOs. While these ideas can be grouped into the same basic categories as global or transnational ideas, it is important to adequately contextualize them. For example, the idea that education is supposed to contribute to people's cultural awareness for a more cohesive society is part of a social-collective conceptualization of 
education policy. Which culture people should be aware of, however, is region-specific. Indeed, education ideas concerned with culture only make sense in a regional context, as there is no "world culture". There is no universal consensus on cultural awareness as a desirable education outcome, so we may expect to find an emphasis on cultural education only in regional organizations.

For regional organizations, it is generally important to set foci for their work. Due to limited budgets and personnel, regional organizations require certain education policy objectives to be prioritized over others in order to be effective. The three Islamic education IOs covered elsewhere in this volume (Chap. 7) provide an example of this process, as they prioritize social and cultural purposes of education over economic ones. Subsequently, it should be expected that SEAMEO is similarly forced to set priorities. Due to the poor economic status of many SEAMEO member states, one may additionally expect that the organization conceptualizes education mainly as a policy field of economic development. Based on the available data, however, I argue that this is not the case.

\section{Exploring SEAMEO: A Decentralized Approach to International Cooperation}

SEAMEO is a regional international organization tasked with facilitating cooperation in education, science, and culture between its member states. Since its inception more than five decades ago, it has grown into one of the most relevant actors in international education policy in Southeast Asia. Its purposes resemble those of similar organizations around the world, which have been modeled after UNESCO, albeit with distinct regional contexts, such as the Islamic World Education, Science, and Culture Organization (ICESCO) and the Arab League Cultural, Educational, and Scientific Organization (ALECSO). The Yearbook of International Organizations classifies SEAMEO as a regionally defined membership organization, meaning that its "Membership and preoccupations [are] restricted to a particular continental or sub-continental region or contiguous group of countries, and [it] covers at least 3 countries or 
includes at least 3 autonomous international bodies" (Union of International Associations 2020). SEAMEO membership reflects this typology, as all 11 of its current member states are located in the Southeast Asian region.

SEAMEO is closely affiliated with the more widely known Association of Southeast Asian Nations (ASEAN), another regional international organization that covers a larger range of policy areas, often with an economic focus. The member states that constitute ASEAN are almost identical to those of SEAMEO, with the exception of Timor-Leste, which is a member of SEAMEO but not of ASEAN. As per its "core values", SEAMEO intends to be "ASEAN's strategic partner for the advancement of education, science and culture" (SEAMEO 2020a). This cooperation is realized via regular coordination meetings, joint projects in education and culture, and memorandums of understanding.

Although the education ministers of its member states make up the SEAMEO Council, which is the organization's highest decision-making body, and the SEAMEO Secretariat as the main administrative body is set up in Bangkok, SEAMEO's work is distinctly decentralized in nature. The practical work "on the ground" is carried out by 26 regional centers, which are spread across all member states. These centers operate as independent organizational units with their own secretariats, budget, and staff, and they report to both the SEAMEO Secretariat as well as the respective ministries of the countries they operate in (see Fig. 8.1). They cover fields as diverse as Open and Distance Learning (covered by the SEAMEO Regional Open Learning Centre (SEAMOLEC)), Southeast Asian Regional Center for Graduate Study and Research in Agriculture (SEARCA), or Tropical Biology (BIOTROP). In total, SEAMEO employs over 1,000 people across all its centers (Interview SEAMEO A 2020).

The decentralized nature of SEAMEO's organizational structure implies the possible existence of many different views and ideas since, in principle, every regional center may have its own distinct motifs. However, most of these centers do not deal specifically with education policy but rather focus on content-based implementation of policy in their respective fields. They do not engage in justifying or reflecting on education policy. 


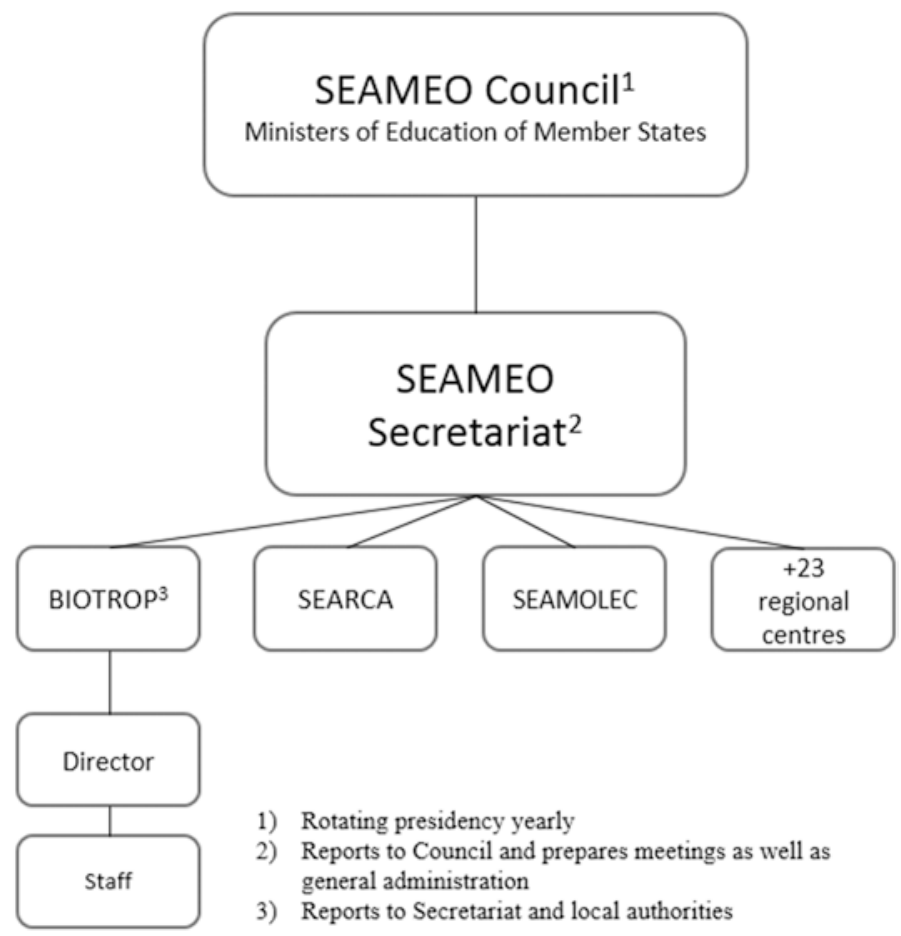

Fig. 8.1 SEAMEO structure. (Own account, data from https://www.seameo.org/)

SEAMEO's member states are very heterogeneous in terms of economic development. While some of them, such as Singapore and Malaysia, have been on the forefront of economic growth in the region, others are among the poorest countries in Asia. Thus, SEAMEO faces the delicate challenge of balancing the educational needs of its developing member states with those of its richer members when designing policy. This diversity gives rise to questions about distributional justice and the balance of power within the organization, both of which are somewhat alleviated through means of unanimous decision-making in the SEAMEO Council (Interview SEAMEO A 2020). Although policy decisions can be taken by qualified majority, decisions that face the objection of even a single member state are rarely adopted. 
As the main international organization for education in the region, SEAMEO is notably well connected both with governments in the region as well as with partner organizations. It is also the main partner for global education IOs operating in the region. SEAMEO's joint projects include cooperation with the United Nations Children's Fund (UNICEF), UNESCO, and the Asian Development Bank (ADB). SEAMEO and UNESCO have been regular partners since the early 1980s, cooperating on a wide range of education projects in Southeast Asia. A recent example is the UNESCO Global Action Programme (GAP) on Education for Sustainable Development (ESD) launched in 2014, which is implemented in the region by SEAMEO (SEAMEO 2020b). For UNICEF, cooperation with SEAMEO has notably increased since 2010 (Interview 1), with one instance being the Southeast Asia Primary Learning Metrics (SEA-PLM) program for grade assessment, which is funded by UNICEF. On the other hand, SEAMEO works with nongovernmental actors like the German Gesellschaft für Internationale Zusammenarbeit (GIZ) and various universities from around the world. As noted by a SEAMEO official in February 2020 in reference to the UN agencies, "If the project is in Southeast Asia, they [UN entities] will contact SEAMEO. Normally, that's the way. ... We are the project implementer" (Interview SEAMEO A 2020).

\section{SEAMEO's Ideas in Education Policy}

IOs often stress that all purposes of education are important and refer to a rather encompassing view on education. In most cases, however, different foci can be found in their documents, statements, and policies. The World Bank and the OECD, for example, pursue an economic focus in education policy (Chap. 5), whereas ICESCO stresses the social purposes of education policy (Chap. 7). SEAMEO, on the other hand, proliferates a balanced and holistic view on education. I refer to this view as holistic because according to SEAMEO, education is supposed to benefit individuals as well as society in regard to both economic and social needs. This is in line with recent definitions of holistic education (Mahmoudi et al. 2012). Concurrently, SEAMEO's education ideas do have their 
own essence, in that education policy is seen as an important tool in preserving the cultural roots of the region in both individuals and society. By recognizing the cultural dimension of education, SEAMEO views itself as uniquely suited to tackle the challenges facing education policy in the region. IOs with a global focus, such as UNESCO, need a partner in the region if their policies are to be successful, because Southeast Asia is a unique setting for education policy and must be treated accordingly.

Education ideas can be grouped into four basic categories or leitmotifs depending on what they deem to be the primary purpose of education and education policy. Education policy enables individual skill formation and self-fulfillment but is also crucial for economic growth on the national level as well as social participation on the individual level. In this section, I argue that although SEAMEO's education ideas partly overlap with the UN's sustainable development agenda, in that it recognizes the social, cultural, and economic purposes of education, it does so with its own distinct references to Southeast Asian culture and regional values. This emphasis on regional culture represents the main difference between SEAMEO's conceptualization of education policy and the one produced by the UN.

The post-2015 global sustainable development agenda encompasses 17 sustainable development goals, of which Goal 4-quality education-is the most relevant for education policy. Goal 4 represents a commitment by the UN member states to "ensure inclusive and quality education for all and promote lifelong learning" because "Education enables upward socioeconomic mobility and is a key to escaping poverty. Education helps reduce inequalities and reach gender equality and is crucial to fostering tolerance and more peaceful societies" (UN 2020, 1). This recent statement displays a holistic view on education, which is comprised of a balanced set of different ideas about what education should primarily achieve, such as social cohesion or economic growth.

SEAMEO, on the other hand, has championed this view on education since its inception back in 1965, referring to a better "quality of life" for the people of Southeast Asia as the main purpose of its existence. The documents reviewed for this chapter contain frequent references to this purpose, stating for example that "[SEAMEO] is mandated to enhance regional understanding and cooperation and unity of purpose among 
SEAMEO Member Countries in order to achieve a better quality of life" (SEAMEO 2017a, xiii, emphasis added). In fact, out of the 15 reviewed documents, only 6 did not include statements on quality of life. It remains vague, however, what the term "quality of life" entails beyond the general notion that education and science are supposed to holistically improve every aspect of people's lives in the region. Therefore, it seems more fruitful to focus on specific statements made by SEAMEO on the social and/ or economic purposes of education.

In SEAMEO's founding charter, the signatory members explicitly note that the organization will "assist in articulating education to the economic and social goals in the individual Member States" (Art. I $\$ 2$ b, emphasis added). Since then, this sentiment has found its way into most publications available for analysis. Below are some examples from different decades:

The benefits of ... education may be derived at various levels. At the personal level, individuals can improve their knowledge and skills for their own betterment, be this in terms of material or moral well-being. The contributions of the individuals could lead to greater productivity and better livelihood of a community .... (SEAMES 1973, 3)

[A] large segment of the population ... require[s] some form of educational service to improve their economic status and the quality of their social participation. (SEAMES 1981, 2)

Education is very important in bringing a better quality of life of people in the region [sic!]. At the individual level, education offers the opportunity for a person to acquire new knowledge, learn relevant skills and pathways to realise personal aspirations. At the macro level, education is strongly linked to economic productivity, technological advancement, higher income, and lowered poverty levels. (SEAMEO 2008, 5)

[Education] can maximise the development of knowledge and skills that enable individuals to attain holistic well-being, sense of responsibility and self-reliance. Ultimately, successful individuals are able to live harmoniously and further contribute to society. (SEAMEO 2017a, iv) 
Unlike other education IOs, there are few instances in which SEAMEO documents would prioritize one aspect of education policy over others. This finding is consistent with statements drawn from an interview with a high-ranking SEAMEO official conducted in February 2020, in which the interviewee stressed that education must be treated as part of both social policy and development or economic policy. The interviewee also subscribed to the idea that education should be seen as a "holistic project" in which different purposes of education need to be fairly balanced. Therefore, neither the social nor the economic dimension is prioritized over the other in education policy (Interview SEAMEO A 2020, 10).

Indeed, it seems that in recent years SEAMEO has started to support this "holistic" nature of education quite explicitly (SEAMEO 2017a, iv), especially in the context of lifelong learning. For example, in its action agenda of 2017, SEAMEO proposed an association of lifelong learning with the objective of developing and implementing "holistic and comprehensive lifelong learning approaches" (SEAMEO 2017b, 36).

Since a holistic view on education encompasses all four basic categories of education ideas (Nagel et al. 2010), evidence of each of these idea groups or leitmotifs should be found in SEAMEO publications. The following section will assess the findings for each category found in SEAMEO's policy publications. When possible, instances where these ideas are highlighted separately instead of where they are intertwined with their counterparts are presented. A standard practice in the publications of education IOs includes listing all imaginable benefits of education when addressing readers; however, it is more noteworthy if an idea is presented separately from others.

Individual skill formation, referring to the development of personal abilities that help boost the productivity and economic livelihood of an individual, is especially present in earlier documents. Here, education primarily ensures equal opportunities in the transnational labor markets for individuals from all kinds of economic backgrounds and increases the general standard of living of people in the region. These ideas are present in publications as early as 1973 (SEAMES 1973, 1). In the context of nonformal education, education policy is "called upon to assist in raising standards of living and in improving the quality of life of the underprivileged" (SEAMES 1981, 4). Identifying the need to educate children and 
youth that do not finish school or have never enjoyed regular schooling, SEAMEO notes that "a large proportion of out-of-school youth and adults do not possess marketable skills" and that occupational training needs to be expanded to empower "the urban and rural underprivileged in raising their standard of living" (SEAMES 1980, 10).

Overall, however, SEAMEO mostly refers to the collective economic benefits of education, if it deviates at all from its emphasis on holistic well-being. These collective purposes of education include economic development and human capital formation. Therefore, education policy needs to be a part of an economy's response to the ever-increasing globalization of national markets and the challenges posed by the transnationalization of human capital. As noted in 2008 by Prof. Dr. Bambang Sudibyo, the then Minister for National Education of the Republic of Indonesia and SEAMEO Council President, "In today's globalised world ..., the people have to be able to respond to the global outlook and be ready to seize global opportunities" (SEAMEO 2008, 5). This idea is displayed in many recent publications (SEAMEO 2011; SEAMEO 2017b; SEAMES 1980). As a poignant example, note this statement from the 2011-2020 SEAMEO Strategic Plan:

SEAMEO recognizes that the ever-changing labour market needs and fastpaced global development pose enormous challenges for Southeast Asia to sustain and upgrade the competitiveness of its human resources. (SEAMEO 2013, 66)

To effectively tackle globalization's challenges, education is the premier tool available to SEAMEO member states. In this context, SEAMEO views itself both as an enabler and a provider for its members, stating that it is "Southeast Asia's largest and most dependable service provider in human resource development" (SEAMEO 2008, 8), with its economic mission being "to nurture human capacities and explore the fullest potentials of people in the region" (ibid.). In sum, "SEAMEO firmly believes that regional strategies should be aimed at benefitting individual member countries while at the same time achieving integration for regional growth" (SEAMEO 2013, 66). 
With respect to the social dimension of education, SEAMEO displays a distinct cultural element to its policy reasoning and its specific recommendations. This idea is based on the notion of the unique nature of the Southeast Asia region, which requires an approach toward education policy specifically tailored to and mindful of this nature. For individuals, education is viewed as a means to promote and attain personal development, a healthy life, and fulfilling participation in society. For societies, education has a huge range of purposes; it can be a catalyst for a healthy, equal, fair, and moral society and a prerequisite for cultural awareness of one's own culture as well as foreign cultures, thereby enabling intercultural dialogue.

Among the benefits presented, the most prominent relate to culturalregional aspects such as local traditions, history, and language. As early as 1973, SEAMEO noted that "education can strengthen ... nation building, preservation and development of cultural heritage and environmental improvements" (SEAMES 1973, 6). To this day, SEAMEO upholds the reproduction and appreciation of cultural roots as one of education's main social purposes (SEAMEO 2013, 2017a, 2017b). According to SEAMEO, a necessary condition for valuable intercultural dialogue both between and within different regions is a society that is aware and appreciative of its own culture. This is especially true for Southeast Asian societies because many of them are either multiethnic, multireligious, or, commonly, both. According to Prof. Dr. Sudibyo, "in ... socio-cultural development, education takes greater significance in multi-ethnic and multi-religious societies. Education can help to raise awareness of commonalities and shared values among different communities" (SEAMEO 2008 , 5). In this way, SEAMEO hopes to create and encourage a shared "unity of purpose" among its member states through education (SEAMEO 1999, 2011, 2013).

Furthermore, SEAMEO views education as a tool to produce and reproduce regional norms and values and to improve social cohesion within its member states. Special attention is regularly given to vulnerable communities and the ways in which they can be empowered by quality education, possibly resulting in a more cohesive and resilient society and providing equal opportunities to people from all kinds of backgrounds. In this context, "vulnerable communities" refers to those that 
suffer from any form of systematic exclusion from the education system. This includes linguistic and/or ethnic minorities, people with special education needs, the economically disadvantaged, or those who live in remote areas without access to regular schooling (SEAMEO 2016, 5). In order to support these communities, SEAMEO has dedicated one of their 7 "priority areas" from 2015-2035 to addressing barriers to inclusion (SEAMEO 2017b, 2017c, 12). As an interviewed official stated, "the target of the ministers ... is how to identify the marginalized learnersthose who are out of school-and bring them back to school" (Interview SEAMEO A 2020, 2).

Overall, there is evidence of all four categories presented above: skill formation, self-fulfilment, wealth of nations, and social right and duty. In the policy publications, however, none of them are presented as being more important to the education ideal of SEAMEO than any of the other categories. This finding is once again consistent with personal accounts. When presented with different purposes of education that were similar to the aforementioned ones, the interviewed official refrained from ranking or weighing them against one another, instead stating that "they are all important ... within our vision and mission" (Interview SEAMEO A 2020, 10).

What then distinguishes SEAMEO from other education IOs if not for a policy focus? From this analysis, it is precisely the holistic nature of SEAMEO's ideal of education that separates it from the bulk of global education IOs. More specifically, the fact that we can observe this "quality of life" approach so early in SEAMEO's publications is unique to this organization. As Niemann (Chap. 5) points out, most education IOs started their activities focusing either on the social dimension of education, like UNESCO did, or on the economic dimension, like the OECD and the World Bank did. SEAMEO, on the other hand, included both social and economic goals for education policy in its charter (see above) and its mission from its very foundation in 1965 onward, whereby both types of goals were granted equal significance. It has since been a consistent proponent of this holistic approach.

Being the largest and most relevant regional education IO in Southeast Asia, SEAMEO furthermore views itself as an advocate for the region's cultural uniqueness, which requires an education system that is mindful 
of and specifically tailored to the nature of the region. This notion can be found in other regional international organizations, such as the Arabic education IOs ALECSO and the Arab Bureau of Education for the Gulf States (ABEGS) (Chap. 7); it is rooted in the belief that Western ideas of education dominate in global education IOs, such as UNESCO, and that these ideas as well as the policies informed by them cannot be as readily applied to Southeast Asia as they can to, say, Western Europe, since they do not take into account cultural-regional contexts. At best, this might render them less effective for Southeast Asia; at worst, they may downright fail in the region. What is needed in the region, then, is a well-rounded education approach made for SEAMEO countries. Two statements made by the SEAMEO Council in 2014 and 2016 with the Vientiane Statement and the Bandung Statement, respectively, call for this "revolutionary" approach to be implemented:

We therefore call for a new paradigm for the development of education in Southeast Asia that will require changes to educational systems that are not only gradual and evolutionary, but also revolutionary while still being rooted in our shared values and traditions. (SEAMEO 2016, 3)

We therefore call for action among the delegations and institutions represented here to work cooperatively in building the region's educational system that is dynamic and resilient amidst current challenges, even as they remain rooted in our shared values and traditions. (SEAMEO 2016, 7)

From these press statements alone, it remains unclear what these cultural roots, values, and traditions entail and what they mean for education policy in the region, apart from their perceived uniqueness. I believe the most comprehensive answer to this lies in the following quotation, worthy of repeating almost in its entirety:

Culture refers to a people's traditions, history, values, and language that make up the culture of a group and which contribute to their identity. Integrated with education, it brings about awareness, appreciation, and understanding of one's national patrimony, which reflects, validates, and promotes the values, world views, and languages of the community's culture. Culture-based education ... intends to respect all forms of knowledge 
and ways of knowing and supporting indigenous people and various ethnicities as individuals and community members in educational practices. (SEAMEO 2017b, 247)

As a result, it seems from these definitions that global standards of education can never fully account for regional contexts. Consequently, culturebased education must be designed regionally with the help of organizations like SEAMEO. It is this role as a facilitator of quality education in Southeast Asia that SEAMEO supposedly intends to fill. The challenge for SEAMEO in doing so is framed as follows: It must balance its education policy between its unique cultural background and a global labor and goods market that is dominated by Western standards and requirements, all while maintaining a well-rounded and balanced approach toward education. Quality education in the SEAMEO region must be "proactive and future-oriented, yet rooted in the values and traditions of the region" (SEAMEO 2017c, 1).

\section{The Content of SEAMEO Education Policy: 7 Priority Areas}

Having established the ideas and leitmotifs found in SEAMEO's documents, how does SEAMEO go about achieving these formulated policy goals? Are these ideas reflected in the content of the organization's policy? As the organization is very active on many fronts, the following section focuses on SEAMEO's “7 Priority Areas” for 2015-2035. These areas were established in 2015 to inform and set the agenda for the next two decades of education policy in the region (SEAMEO 2017c). Table 8.1 provides a summary of the priority areas.

The first two of these priorities are targeted primarily at the aforementioned vulnerable groups and local communities, which may be excluded from learning opportunities due to systemic factors. They explicitly target these segments of the population to achieve a more cohesive and just society with equal opportunities for all learners (SEAMEO 2017c, ii). It could be argued that the same is true for Priority 3, because national emergencies, such as natural disasters or wars, tend to hit vulnerable communities much harder than others. Priority 4 is the only area with a 
Table 8.1 SEAMEO's priority areas in education

\begin{tabular}{ll}
\hline & Title \\
\hline Priority 1 & Achieving universal early childhood care and education \\
Priority 2 & Addressing barriers to inclusion \\
Priority 3 & Resiliency in the face of emergencies \\
Priority 4 & Promoting technical and vocational education and training \\
Priority 5 & Revitalizing teacher education \\
Priority 6 & Harmonizing higher education and research \\
Priority 7 & Adopting a twenty-first-century curriculum \\
\hline
\end{tabular}

From SEAMEO (2017c)

strictly economic focus, aiming to provide the people of the region with suitable skills for the labor market and enabling workers' global mobility. Priorities 5 and 6 are formulated rather generally and it remains uncertain whether SEAMEO has a specific focus in mind here. They are essentially "meta" — or process-related—goals, in that they stress the need to reform the education system in the SEAMEO region using an integrated approach that sets region-wide standards, best practices, and frameworks across all member states. Finally, the justification for Priority 7 almost reads like a synopsis of the analysis presented in Chap. 7. By means of an adequate curriculum to be taught in the education institutions of the region, SEAMEO aims to achieve both its social and economic goals while accounting for its cultural roots and values. Thus, adopting a twenty-first-century curriculum means "pursuing a radical reform through systematic analysis of knowledge, skills and values needed to effectively respond to changing global contexts, particularly to the everincreasing complexity of the Southeast Asian social-cultural and political environment" (SEAMEO 2017c, ii).

In order to effectively monitor implementation of the seven priority areas in the member states, SEAMEO uses a percentage-based target system. Education projects connected to the seven areas are reported during the yearly meeting of member state vice ministers of education. They are then recorded and given a contribution percentage value, enabling the Secretariat to track the progress toward all areas in the various member countries (Interview SEAMEO A 2020). Best practices and outstanding projects are highlighted and published in documents such as the 2017 report "7 Priority Areas-Implementation by SEAMEO Member Countries". 
Generally, the priority areas fit quite well with the evidence presented in Chap. 7. This is especially true for Priority 7. Ideally, the analysis should be complemented by an assessment of SEAMEO's budget. After all, action (i.e. financing) may sometimes speak louder than words. Does SEAMEO allocate its budgetary items in a way that pairs well with its stated goals and ideals in education policy? Unfortunately, obtaining the budget for the SEAMEO Secretariat proved to be difficult. Furthermore, due to the decentralized structure of the organization, in which every regional center has its own budget co-funded by the state it is located in, the Secretariat's budget would not tell the whole story-unless one were to obtain all 26 regional centers' budgets as well.

\section{Conclusion}

This chapter has argued that SEAMEO proliferates a holistic, encompassing, and balanced ideal of education in which both social and economic purposes of education are relevant on the individual and societal levels. Furthermore, there is evidence of a special, region-specific twist to SEAMEO's leitmotifs in education policy that manifests itself in the emphasis of cultural values and traditional norms rooted in the regional context of Southeast Asia. The importance of culture in education for people in the region requires a mindful approach toward education policy, which takes such elements into account in order to be successful.

Combined with the findings from the chapter on the Islamic education organizations (Chap. 7), the evidence hints at a more general development in regard to regional education IOs. Regional organizations, like SEAMEO, are keen on reaping the developmental benefits of globalization but at the same time are unwilling to sacrifice their cultural roots, values, or traditions for it. The result is a delicate act of balancing between these two worlds. Further research is required to solidify the theoretical implications of the data presented here. How is the distinct cultural element in both SEAMEO's education ideas as well as in those of other regional or cultural organizations related to globalization? Are these developments expressions of a "new regionalism" or "in-group orientation" in international politics? Is there a countermovement against 
globally proliferated Western education ideals, or are these exceptional rather than representative cases for the interaction between the global and the regional? Future research needs to find answers to these questions if a coherent picture is to be established of how regional organizations react to globalization as well as to the dominance of Western ideals in education policy.

\section{References}

Barnett, Michael, and Martha Finnemore. 1999. The Politics, Power, and Pathologies of International Organizations. International Organization 53 (4): 699-732.

- 2004. Rules for the World: International Organizations in Global Politics. New York: Cornell University Press.

Bauer, Steffen. 2006. Does Bureaucracy Really Matter? The Authority of Intergovernmental Treaty Secretariats in Global Environmental Politics. Global Environmental Politics 6 (1): 23-49.

Goldstein, Judith, and Robert O. Keohane, eds. 1993. Ideas and Foreign Policy: Beliefs, Institutions, and Political Change. Cornell: Cornell University Press.

Hawkins, Darren G., David A. Lake, Daniel L. Nielson, and Michael J. Tierney. 2006. Delegation and Agency in International Organizations. Cambridge: Cambridge University Press.

Krippendorff, Klaus. 2004. Content Analysis. An Introduction to its Methodology. 2nd ed. Thousand Oaks: SAGE Publications.

Mahmoudi, Sirous, Ebrahim Jafari, Hasan Ali Nasrabadi, and Mohmmd Javad Liaghatdar. 2012. Higher Education: An Approach for 21 Century. International Education Studies 5 (2): 178-186.

Martens, Kerstin, and Dennis Niemann. 2021. Global Discourses, Regional Framings and Individual Showcasing: Analyzing the World of Education IOs. In International Organizations in Global Social Governance, ed. Kerstin Martens, Dennis Niemann, and Alexandra Kaasch. Basingstoke: Palgrave Macmillan.

Nagel, Alexander-Kenneth, Kerstin Martens, and Michael Windzio. 2010. Introduction-Education Policy in Transformation. In Transformation of Education Policy, ed. Kerstin Martens, Alexander-Kenneth Nagel, Michael Windzio, and Ansgar Weymann, 3-27. Basingstoke: Palgrave Macmillan. 
Schreier, Margrit. 2014. Qualitative Content Analysis. In The SAGE Handbook of Qualitative Data Analysis, ed. Uwe Flick, 170-183. Thousand Oaks: SAGE Publications.

SEAMEO. 1965. Charter. Bangkok: SEAMEO. 1999. Annual Report 1997/1998. Bangkok: SEAMEO.

- 2008. SEAMEO Accomplishment Report FY2006/2007. Bangkok: SEAMEO.

- 2011. Annual Report 2009/2010. Bangkok: SEAMEO. 2013. Strategic Plan 2011-2020. Bangkok: SEAMEO. 2016. Strategic Dialogue for Education Ministers. Bangkok: SEAMEO. - 2017a. SEAMEO Basic Education Standards: Common Core Regional Learning Standards (CCRLS) in Mathematics and Science. Bangkok: SEAMEO. - 2017b. Action Agenda for the SEAMEO 7 Priority Areas. Bangkok: SEAMEO.

- 2017c. 7 Priority Areas_Implementation by SEAMEO Member Countries. Bangkok: SEAMEO.

- 2020a. About SEAMEO.. Accessed 19 August 2020. https://www. seameo.org/Main_about/90.

- 2020b. Education for Sustainable Development.. Accessed 30 October 2020. https://www.seameo.org/Main_programme/217.

SEAMES. 1973. Proposal for a Study of Non-Formal Education in the SEAMEO Region. Bangkok: SEAMES.

- 1980. Revised Development Plan for SEAMEO Non-Formal Education Programme 1980-1983. Bangkok: SEAMES.

- 1981. Proposed Development Plan for the SEAMEO Programme in NonFormal Education. Bangkok: SEAMES.

Union of International Associations. 2020. Type 1 Codes.. Accessed 19 August 2020. https://ybio.brillonline.com/ybguide/type1.

United Nations. 2020. Quality Education: Why It Matters.. Accessed 2 September 2020. https://www.un.org/sustainabledevelopment/wp-content/uploads/ 2017/02/4_Why-It-Matters-2020.pdf. 
Open Access This chapter is licensed under the terms of the Creative Commons Attribution 4.0 International License (http://creativecommons.org/licenses/ by/4.0/), which permits use, sharing, adaptation, distribution and reproduction in any medium or format, as long as you give appropriate credit to the original author(s) and the source, provide a link to the Creative Commons licence and indicate if changes were made.

The images or other third party material in this chapter are included in the chapter's Creative Commons licence, unless indicated otherwise in a credit line to the material. If material is not included in the chapter's Creative Commons licence and your intended use is not permitted by statutory regulation or exceeds the permitted use, you will need to obtain permission directly from the copyright holder.

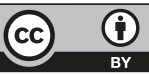

